Research Article

\title{
Meta-Analysis of ERCC1 Protein Expression and Platinum Chemosensitivity in Non-Small-Cell Lung Cancer
}

\author{
Guoping Li $\mathbb{D i}^{1}$ and Dan Cheng $\mathbb{D}^{2}$ \\ ${ }^{1}$ Department of Respiration, Tongde Hospital of Zhejiang Province, No. 234 Gucui Road, Xihu District, Hangzhou, \\ Zhejiang 310012, China \\ ${ }^{2}$ Department of Respiration, Central Hospital of Haining, Zhejiang Province People's Hospital Haining Hospital, \\ No. 758 Chang'an Road, Chang'an Town, Haining, Zhejiang 314408, China \\ Correspondence should be addressed to Dan Cheng; 109415425@qq.com
}

Received 5 November 2019; Revised 10 February 2020; Accepted 10 February 2020; Published 30 April 2020

Academic Editor: Jamal A. Mahajna

Copyright ( $) 2020$ Guoping Li and Dan Cheng. This is an open access article distributed under the Creative Commons Attribution License, which permits unrestricted use, distribution, and reproduction in any medium, provided the original work is properly cited.

\begin{abstract}
Objective. To carry out the meta-analysis on the relationship between the expression of nucleotide excision repair crosscomplementary enzyme 1 (ERCC1) protein and platinum chemosensitivity in patients with advanced non-small-cell lung cancer (NSCLC). Methods. The literature on the expression of ERCC1 and platinum chemosensitivity in patients with advanced NSCLC was searched in computer, which was published from January 2009 to August 2019 on the databases such as China Journal Fulltext Database (CJFD), China National Knowledge Infrastructure (CNKI), Wanfang Database, VIP, PubMed, EMBASE, and others. Stata 15.0 was used for statistical analysis, and ethnicity subgroup analysis was taken. Results. Finally, 14 studies were included and 1337 patients were involved, of which 697 were ERCC1 positive, with a positive rate of 53.5\%. The combined OR was 0.53 (95\% CI: $0.30 \sim 0.79 ; P<0.01$ ). The results of ethnicity subgroup analysis showed that there was no significant difference, with OR of 0.50 (95\% CI: 0.31 0.82; $P=0.001$ ) in Asian population and OR of 0.56 (95\% CI: 0.30 1.07) in Caucasian population. Conclusion. The sensitivity to platinum chemotherapy in patients with ERCC1 protein negative expression in the middle and late stages of NSCLC is better than that in patients with positive expression, especially in Asian population. There is no correlation in Caucasian population.
\end{abstract}

\section{Introduction}

Lung cancer is one of the most common malignant tumors at present, and the number of patients with which is increasing rapidly all over the world. It has the highest mortality rate in the world, with the annual deaths of more than 1 million [1]. In addition, according to some relevant reports, it is currently the fastest growing disease in the world in terms of morbidity and mortality, posing a serious threat to human health. According to the pathological features, the lung cancer can be divided into smallcell lung carcinoma (SCLC) and non-small-cell lung carcinoma (NSCLC) $[2,3]$, among which NSCLC is the major one, mainly including squamous cell carcinoma, adenocarcinoma, and large cell carcinoma. In the past 20 years, the morbidity of lung cancer in China's rural regions as well as the cities is increasing significantly, especially that of NSCLC $[4,5]$. Nowadays, the clinical treatment of lung cancer is based on platinum drugs. There is no significant difference in the therapeutic effect of these platinum-containing regimens. The drug response rate is only $30 \%$ to $40 \%$, and the median survival time is $8-10$ months; the 5 -year survival rate is less than $15 \%$ [6]. Clinical studies have shown that the prognosis of advanced NSCLC chemotherapy is related to stage, sex, age, physical status (PS), and other factors, but these clinical factors are obviously not accurate enough. The sensitivity of NSCLC with the same pathological type and stage to the same chemotherapy is significantly different. With the advance of pharmacogenetics and 
pharmacogenomics, we can study on the level of singlenucleotide gene polymorphism of patient gene and gene expression of tumor tissue, so that the more accurate prediction of sensitivity and prognosis of chemotherapy in patients can be obtained $[7,8]$. As the theoretical knowledge is accumulated and improved, the focus of clinical research of related scholars will be to develop a treatment scheme that can further improve the pertinence of platinum drugs on top of the existing treatment level. Tumor is resulting from abnormal mechanism of cell differentiation, proliferation, and death. Although the mechanism of tumorigenesis is not so clear, it is known that the damage of DNA, the abnormality of gene structure, and the resulting changes in the expression or function of oncogenes as well as tumor suppressor genes are the necessary prerequisites for malignant transformation of cells. Therefore, DNA repair is a protective response of living cells to a variety of damage to their genomes through various pathways. To a large extent, it ensures the stability, replication, and transcription fidelity along with the accuracy of genetic material and makes the life activities proceeding normally. However, many anticancer cytotoxic drugs target cell DNA, so the abnormal repair ability of it is closely related to the formation of tumor resistance [9]. The development of tumor cells to platinum resistance is caused by many factors, which may include the decrease of drug accumulation, the increase of glutathione level as well as metallothionein, and the improvement of DNA repair capacity (DRC) [10]. Among them, DRC is a very important influencing factor. The repair capacity of damaged DNA has great variability among different individuals and at different ages, which leads to the difference of sensitivity of tumor cells to DNA-related cytotoxic drugs [11]. In recent years, basic studies have indicated that nucleotide excision repair system (NER) is one of the main repair pathways after platinum-induced DNA damage in tumor cells [12]. Excision repair cross-complementation group 1 (ERCC1), a destructive repair enzyme of DNA, is a key factor in NER, and its expression is an important factor in the sensitivity of platinum drugs [13]. At present, there are many academic studies on the relationship between ERCC1 protein expression and platinum chemosensitivity of lung cancer, but the results are inconsistent or controversial. Therefore, in this study, meta-analysis was used to explore their relationship in patients with advanced NSCLC in order to avoid blind selection of chemotherapy regimens and provide a theoretical basis for clinical treatment.

\section{Material and Methods}

2.1. Literature Retrieval. With the keywords of lung cancer, ERCC1, and platinum, the literature from January 2009 to August 2019 was searched in the databases such as CJFD, CNKI, Wanfang Database, VIP, PubMed, and EMBASE. The preliminary screening was done mainly by reading the abstracts. And then the references of the literature that met the inclusion criteria were carefully read to get the wanted articles. The selected literature was published in Chinese or English.

\subsection{Selection Criteria}

2.2.1. Literature Inclusion Criteria. (1) The subjects were patients with advanced NSCLC, that is, patients at clinical stages II-IV. (2) The case-control study on the expression of ERCC1 protein and efficacy of NSCLC in platinum chemotherapy was analyzed. (3) NSCLC was primary lung cancer and diagnosed by pathology or cytology. (4) The test method of the protein expression of ERCC1 was immunohistochemical (IHC) staining. (5) The WHO standard was used as the evaluation standard of curative effect, with the complete remission + partial mitigation as the total effective rate. (6) For the multiple reports of the same author, the latest or most complete reports were used. (7) The Chinese literature was those included in the Core Database of Peking University Library.

2.2.2. Literature Exclusion Criteria. (1) The study was on animal experiment or the lung cancer cell line. (2) The study was on the nonprimary lung cancer, such as metastatic or recurrent cancer. (3) The study was on the SCLC. (4) The study was about chemotherapy with nonplatinum regimen, with less than 2 courses of chemotherapy. (5) The study was on the relationship between the expression of ERCC1 protein and the efficacy of platinum chemotherapy, such as ERCC1 mRNA and ERCC1 gene polymorphism.

2.3. Data Extraction and Quality Evaluation. All the following information was extracted from the included literature: (1) general information: it includes researchers, publication time, and the country; (2) the literature characteristics: clinical staging, chemotherapy regimen, the number of ERCC1-positive and ERCC1-negative cases, and the number of effective cases of chemotherapy; and (3) methodological features: it includes ERCC1 detecting methods, cutoff value, statistical methods, and results. As the inclusion of the literature is retrospective studies, there are no random and blind requirements. The quality of the literature was evaluated according to the Newcastle-Ottawa Scale (NOS) [14], with low-quality ones under 6 stars and high-quality ones of 6 stars or above. Only the literature of high quality was included in this study. Two evaluators evaluated the literature independently and cross-checked. When there were divergences, the consensus was reached through discussion.

2.4. Statistical Methods. The meta-analysis was carried out by Stata 15.0 software. The OR and 95\% CI, as the effect size, were calculated to represent the results. $Q$ test was used to test the heterogeneity of the results. If $I^{2} \geq 50 \%$ or $P \leq 0.05$, it is considered that there was heterogeneity, and the randomeffects model was used. If $I^{2}<50 \%$ and $P>0.05$, it was considered that there was no heterogeneity, and the fixedeffects model could be used for data consolidation. $Z$ test was 
used to test the significance of the combined OR value. In this meta-analysis, the evaluation of publication bias of the included literature was judged by whether the funnel plot was symmetrical or not. Funnel plot was to use the standard error of each study log (OR) to draw its OR value. If the funnel plot was asymmetric, there may be publication bias. Egger's test and Begg's test were used to test the publication bias.

\section{Results}

3.1. Literature Retrieval Results. The databases were searched comprehensively, and then, the retrieval results were cross-checked. The selected literature was screened in strict accordance with the exclusion criteria and the quality control requirements after reading carefully. At the end, 14 articles [15-28] were chosen into the meta-analysis, with the specific screening process in Figure 1 and the basic characteristics of the included literature in Table 1. Of the 1337 patients with non-small-cell lung cancer, 697 were positive, with a positive expression rate of $53.5 \%$.

\subsection{Relationship between ERCC1 Expression and Sensitivity} to Platinum Chemotherapy in NSCLC. The meta-analysis of the included 14 studies showed that there was statistical heterogeneity among the studies $\left(P \leq 0.001 ; I^{2}=61.2 \%\right)$. Using the random-effect model to analysis, the forest plot was obtained, which is shown in Figure 2. The complete remission + partial remission rate of 14 studies (1337 cases) reported in patients with NSCLC after chemotherapy indicated that the patients with high expression of ERCC1 were less sensitive to chemotherapy than those with low expression, with the combined OR of 0.53 (95\% CI: $0.30 \sim 0.79 ; P<0.01)$. The results of ethnicity subgroup analysis showed that, for Asian population, there was a significant difference with the combined OR of 0.50 (95\% CI: $0.31 \sim 0.82 ; P=0.001)$. For Caucasian population, with the combined OR of 0.56 (95\% CI: 0.30 1.07), the difference was not statistically significant, as shown in Table 2 . The results demonstrated that there was a correlation between the expression of ERCC1 and platinum sensitivity in patients with advanced NSCLC. The chemotherapy sensitivity of patients with low expression of ERCC1 was higher than that of patients with high expression of platinum, especially in Asian population. However, no correlation was found in the Caucasian population. In order to better explore the source of heterogeneity, we conducted a subgroup analysis of tumor staging, excluding patients with stage II of non-small-cell lung cancer, and then analyzed. The results showed that (Table 2), stage III-IV patients were analyzed alone, and heterogeneity decreased, $\mathrm{OR}=0.57$ (95\% CI: 0.39-0.84, $P<0.05)$. This showed that tumor staging was one of the sources of heterogeneity.

3.3. Publication Bias Analysis. The literature was analyzed by funnel plot, and the symmetry of the plot was analyzed by Egger's test and Begg's test. The specific results are shown in Table 2 and Figure 3, which indicated that the funnel plot

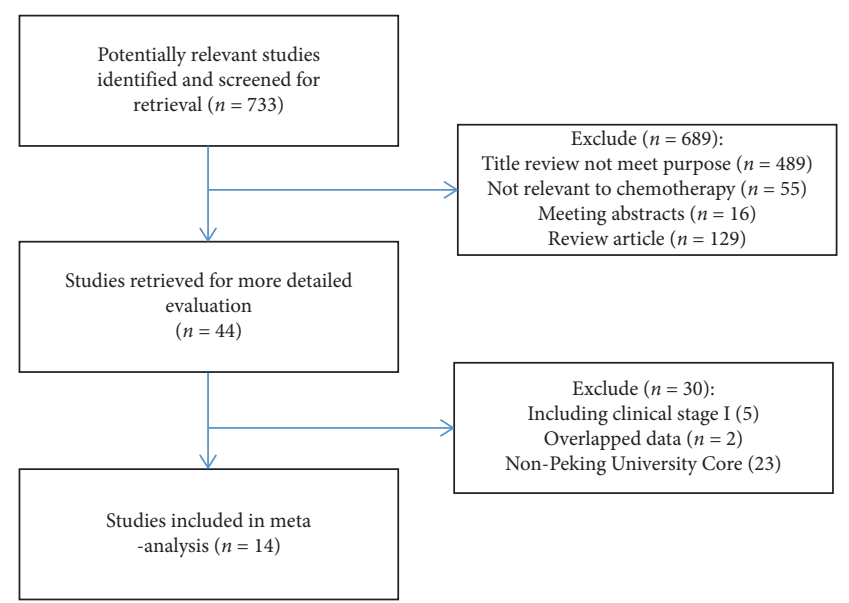

Figure 1: A flow diagram of the study selection process.

was basically symmetrical, and the $P$ value of Begg's test was more than 0.05 , while the $P$ value of Egger's test was slightly less than 0.05 so that there was partial publication bias.

3.4. Sensitivity Analysis. The results of sensitivity analysis are shown in Figure 4. Each study was excluded one by one, and the results of meta-analysis showed that there was no significant change in the combined effect. The results of sensitivity analysis were also stable in Asian population and Caucasian population, meaning that the included 14 articles were stable.

\section{Discussions}

Platinum resistance is caused by a variety of factors, including the decrease of drug accumulation, the increase of drug detoxification (such as glutathione and metallothionein), the enhancement of DRC, and the increase of platinum-DNA adducts [29]. Besides, a number of studies have shown that DNA repair is the main cause of platinum resistance in the treatment of platinum drugs. DRC is the capacity to stabilize the related cellular response by restoring the structure of normal DNA sequence and maintaining genetic information. DNA damage repair genes can repair DNA damage caused by different reasons, thus protecting the integrity of genetic information. In the process of cancer treatment, DNA is the target molecule of many kinds of anticancer drugs; therefore, its abnormal damage as well as repair ability is closely related to the formation of tumor drug resistance [30]. NER is the main way of DNA repair in mammalian cells, and it is a necessary factor to protect the host from tumor invasion, the low expression of which is associated with the susceptibility to many kinds of tumors [31]. Further research studies indicate that the antitumor effect of platinum drugs is not related to platinum-DNA interchain crosslink, but more closely to platinum-DNA chain, which is mainly repaired by NER system [32]. Platinum resistance is caused by the repair ability of DNA. The removal of platinum drugs through NER leading to DNA intrachain adducts is considered to be the main mechanism of platinum drug resistance [12]. Therefore, NER plays a key 
TABle 1: Characters of included studies.

\begin{tabular}{|c|c|c|c|c|c|c|c|c|c|c|c|}
\hline \multirow{2}{*}{$\begin{array}{l}\text { First } \\
\text { author }\end{array}$} & \multirow[b]{2}{*}{ Year } & \multirow[b]{2}{*}{ Country } & \multirow[b]{2}{*}{ Method } & \multirow[b]{2}{*}{ Stage } & \multirow{2}{*}{$\begin{array}{l}\text { Therapy } \\
\text { regimen }\end{array}$} & \multirow{2}{*}{$\begin{array}{c}\text { Chemotherapy } \\
\text { course }\end{array}$} & \multicolumn{2}{|c|}{ ERCC1 positive } & \multicolumn{2}{|c|}{ ERCC1 negative } & \multirow{2}{*}{$\begin{array}{l}\text { NOS } \\
\text { score }\end{array}$} \\
\hline & & & & & & & Response & $\begin{array}{c}\text { No } \\
\text { response }\end{array}$ & Response & $\begin{array}{c}\text { No } \\
\text { response }\end{array}$ & \\
\hline Lee & 2009 & Korea & IHC & $\begin{array}{l}\text { IIIB- } \\
\text { IV }\end{array}$ & $\begin{array}{l}\text { Platinum- } \\
\text { based }\end{array}$ & $\geq 2$ & 11 & 17 & 7 & 15 & 8 \\
\hline Ota & 2009 & Japan & IHC & IV & $\begin{array}{l}\text { Platinum- } \\
\text { based }\end{array}$ & $\geq 2$ & 26 & 74 & 15 & 41 & 8 \\
\hline Azuma & 2009 & Japan & IHC & $\begin{array}{l}\text { IB- } \\
\text { IIIB }\end{array}$ & $\begin{array}{l}\text { Cisplatin- } \\
\text { based }\end{array}$ & $\geq 2$ & 6 & 10 & 15 & 3 & 8 \\
\hline Wang & 2009 & China & IHC & $\begin{array}{l}\text { IIIB- } \\
\text { IV }\end{array}$ & $\begin{array}{l}\text { Cisplatin- } \\
\text { based }\end{array}$ & $\geq 2$ & 12 & 13 & 17 & 11 & 7 \\
\hline Shan & 2009 & China & IHC & $\begin{array}{l}\text { IIIB- } \\
\text { IV }\end{array}$ & $\begin{array}{l}\text { Platinum- } \\
\text { based }\end{array}$ & $\geq 2$ & 7 & 22 & 33 & 19 & 7 \\
\hline Wang & 2009 & China & IHC & III & $\begin{array}{c}\text { Cisplatin- } \\
\text { based }\end{array}$ & $\geq 2$ & 3 & 11 & 9 & 4 & 6 \\
\hline Wang & 2010 & China & IHC & $\begin{array}{l}\text { IIIB- } \\
\text { IV }\end{array}$ & $\begin{array}{l}\text { Platinum- } \\
\text { based }\end{array}$ & $\geq 2$ & 14 & 29 & 44 & 37 & 8 \\
\hline $\mathrm{Li}$ & 2010 & China & IHC & $\begin{array}{l}\text { IIIB- } \\
\text { IV }\end{array}$ & $\begin{array}{c}\text { Cisplatin- } \\
\text { based }\end{array}$ & $\geq 2$ & 3 & 30 & 11 & 27 & 7 \\
\hline Yang & 2011 & China & IHC & $\begin{array}{l}\text { IIIB- } \\
\text { IV }\end{array}$ & $\begin{array}{l}\text { Cisplatin- } \\
\text { based }\end{array}$ & $\geq 2$ & 4 & 16 & 13 & 14 & 7 \\
\hline Vassalou & 2013 & Greece & IHC & $\begin{array}{l}\text { IIIB- } \\
\text { IV }\end{array}$ & $\begin{array}{l}\text { Platinum- } \\
\text { based }\end{array}$ & $\geq 2$ & 13 & 42 & 14 & 25 & 8 \\
\hline Fumie & 2013 & Australia & IHC & III-IV & $\begin{array}{l}\text { Platinum- } \\
\text { based }\end{array}$ & $\geq 2$ & 5 & 23 & 8 & 15 & 8 \\
\hline Gao & 2013 & China & IHC & $\begin{array}{l}\text { IIIA- } \\
\text { IV }\end{array}$ & $\begin{array}{l}\text { Platinum- } \\
\text { based }\end{array}$ & $\geq 2$ & 21 & 54 & 19 & 53 & 7 \\
\hline Han & 2017 & Korea & IHC & $\begin{array}{l}\text { IIIB- } \\
\text { IV }\end{array}$ & $\begin{array}{l}\text { Platinum- } \\
\text { based }\end{array}$ & $\geq 2$ & 50 & 127 & 26 & 76 & 8 \\
\hline Honma & 2018 & Brasil & IHC & III-IV & $\begin{array}{c}\text { Platinum- } \\
\text { based }\end{array}$ & $\geq 2$ & 5 & 9 & 13 & 19 & 8 \\
\hline
\end{tabular}

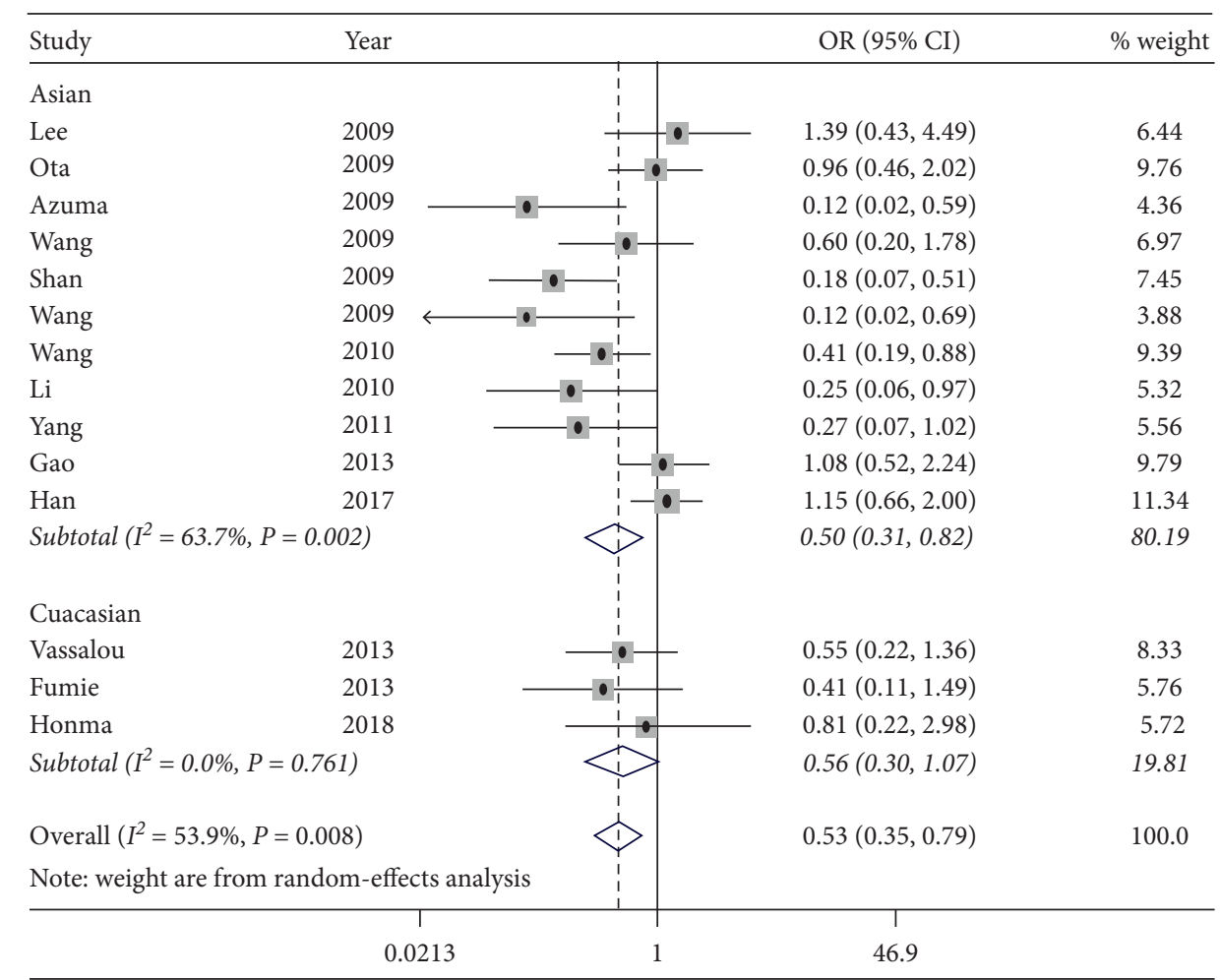

FIGURE 2: Forest plot for the association between ERCC1 expression and platinum chemosensitivity of NSCLC. 
TABLE 2: Meta-analysis between ERCC1 expression and platinum chemosensitivity of NSCLC.

\begin{tabular}{lcccccccccc}
\hline Items & Subgroup & $n$ & OR & $95 \%$ CI & $P$ & $I^{2}$ & $\begin{array}{c}P \text { for } \\
\text { heterogeneity }\end{array}$ & $\begin{array}{c}\text { Analysis } \\
\text { model }\end{array}$ & $\begin{array}{c}P \text { for publication bias } \\
\text { (Egger) }\end{array}$ & $\begin{array}{c}P \text { for publication bias } \\
\text { (Begg) }\end{array}$ \\
\hline Overall & & 14 & 0.53 & $0.30 \sim 0.79$ & $<0.001$ & 53.9 & 0.008 & REM & 0.014 & 0.063 \\
Ethnicity & Asian & 11 & 0.5 & $0.31 \sim 0.82$ & 0.001 & 63.7 & 0.002 & REM & 0.027 & 0.161 \\
Tumor & Caucasian & 3 & 0.56 & $0.30 \sim 1.07$ & 0.088 & 0.0 & 0.839 & FEM & 0.867 & 0.602 \\
stage & III-IV & 13 & 0.57 & $0.39 \sim 0.84$ & 0.005 & 50.0 & 0.02 & REM & 0.029 & NA \\
\hline
\end{tabular}

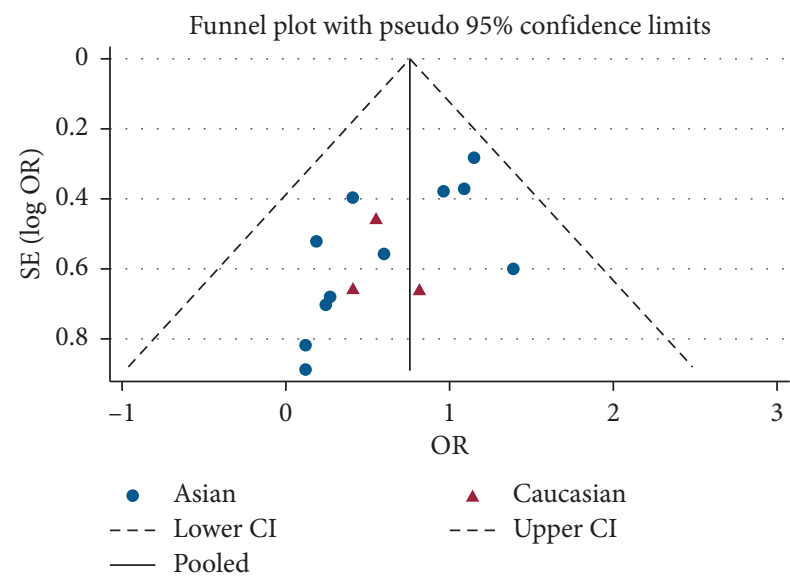

FIGURE 3: Funnel plot for the assessment of publication bias.

role in platinum resistance. Enhancement of NER is an important mechanism leading to cisplatin resistance [33]. ERCC1, a destructive repair enzyme of DNA, is one of the key enzymes in the main part of the helix complex, which is involved in the process of identifying the damaged site. ERCC1-XPD heterodimer formed by ERCC1 protein and $\mathrm{XPD}$ is a $5^{\prime}-3^{\prime}$ DNA restriction endonuclease in NER [34]. In addition, it also plays a certain role in DNA repair connection and internal chain cross repair [35]. Some researchers have found that cisplatin-based chemotherapy can prolong the survival time of patients with no or relatively low expression of ERCC1 in NSCLC cells. In 2006, Olaussen [36] first reported that among the patients with NSCLC complete resection, those with low expression of ERCC1 in tumor specimens had a poor prognosis, but could benefit from chemotherapy containing cisplatin. Those with high expression of ERCC1 had a better prognosis, but it was difficult to benefit from adjuvant chemotherapy. After that, it has been confirmed that, in the early stage of NSCLC, the 5-year survival time and median survival time in the ERCC1 positive group are longer than those in the opposite group. It is considered that the low expression of ERCC1 is a sign of high invasiveness of tumor, and the prognosis is often poor [37]. However, the research of Sad et al. [38] showed that, in the late stage of NSCLC, the 5-year survival time and median survival time in the ERCC1 negative group were longer than those in the opposite group. By analyzing the relationship between the expression of ERCC1 protein in tumor resection samples of NSCLC patients at stage I IIIA and postoperative survival, and taking the postoperative survival time as the final index to study the difference of curative effect in the chemotherapy group, Wang et al. [39] discussed the significance of ERCC1 expression in judging the prognosis of different patients and the existence of cisplatin resistance. It was suggested that the prognosis of patients with ERCC1 $(+)$ expression at stage I was better than that of patients with ERCC1 (-). On the contrary, for NSCLC patients with platinum chemotherapy in stage I and IIIA, the survival time of those with low ERCC1 expression was longer than that of patients with high ERCC1 expression. Thus, there may be biphasic reactions in different stages of NSCLC patients. In this way, the study conducts a meta-analysis on the relationship of the expression of ERCC1 and the chemosensitivity of platinum drugs in patients with advanced NSCLC, in order to comprehensively evaluate the comprehensive effect of ERCC1 protein expression on middleand late-stage patients with NSCLC. Another purpose of the study is to provide evidence-based theory for clinical treatment.

The meta-analysis includes 14 articles [15-28], consisting of 1337 NSCLC patients, with the total positive rate of ERCC 1 of $52.1 \%$. The results show that there is a correlation between the high expression of ERCC1 and the chemosensitivity of platinum in the middle and late stages of NSCLC. The low expression of ERCC1 is more sensitive to platinum chemotherapy in the middle and late stages of NSCLC than that of high expression. The same results are found in Asian and Caucasian subgroups. From the perspective of statistical heterogeneity, the difference is statistically significant, so that there is a certain degree of statistical heterogeneity. In terms of publication bias, the funnel plot is basically symmetrical and Egger's test shows that the $P$ value is slightly less than 0.05 , so there is a partial publication bias. Each study is excluded one by one, and meta-analysis is used. Then, the sensitivity analysis shows that there is no significant change in the combined effect, indicating that the stability of the included study is good. It can be seen that the conclusion drawn from the study is relatively reliable. However, considering that there are few studies on Caucasian population, and their OR values are low, with the upper limit of $95 \%$ confidence interval only slightly greater than 1. Therefore, the conclusion of Caucasian population still needs to be treated with caution. The study of Dong et al. [40] on the expression of ERCC1 and the prognosis of platinum chemotherapy in patients with advanced NSCLC indicates that the 5-year survival rate and median survival time of patients with low expression of ERCC1 are higher than those of patients with high expression, which is consistent with the results of chemosensitivity in this study. 


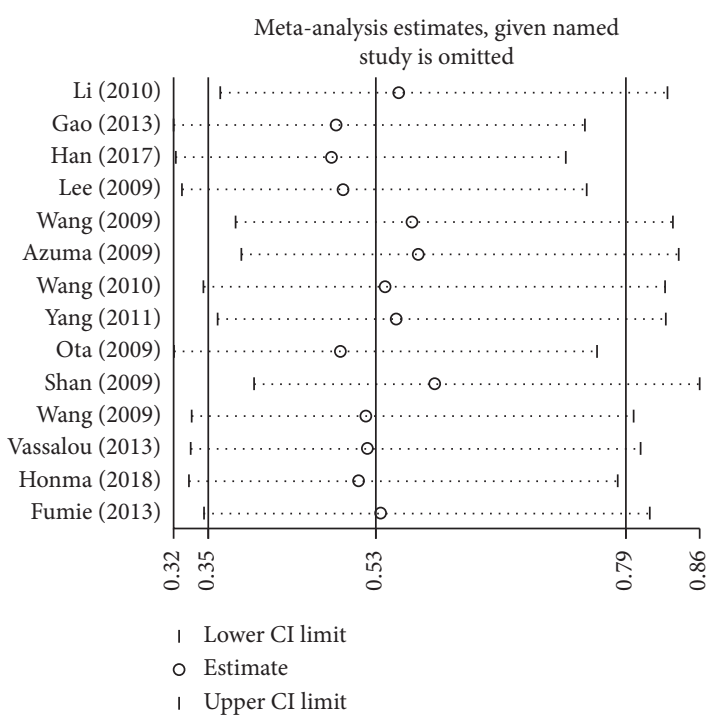

(a)

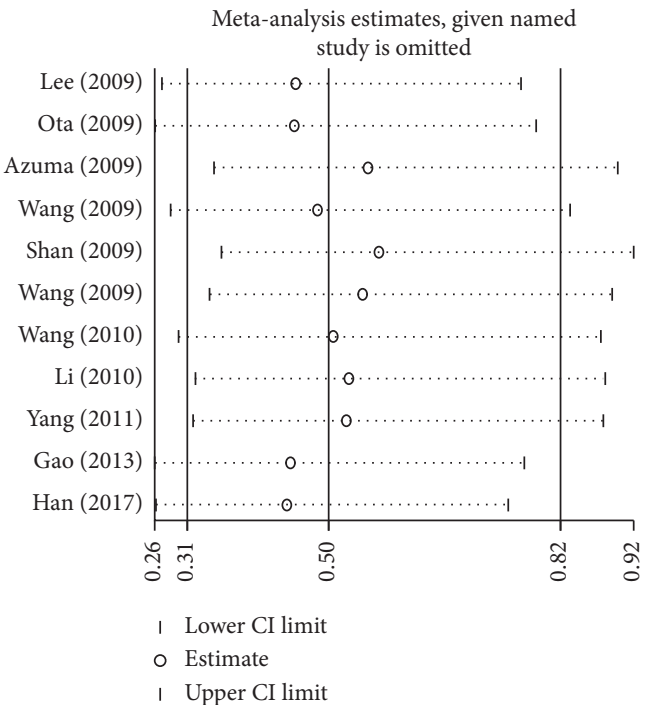

(b)

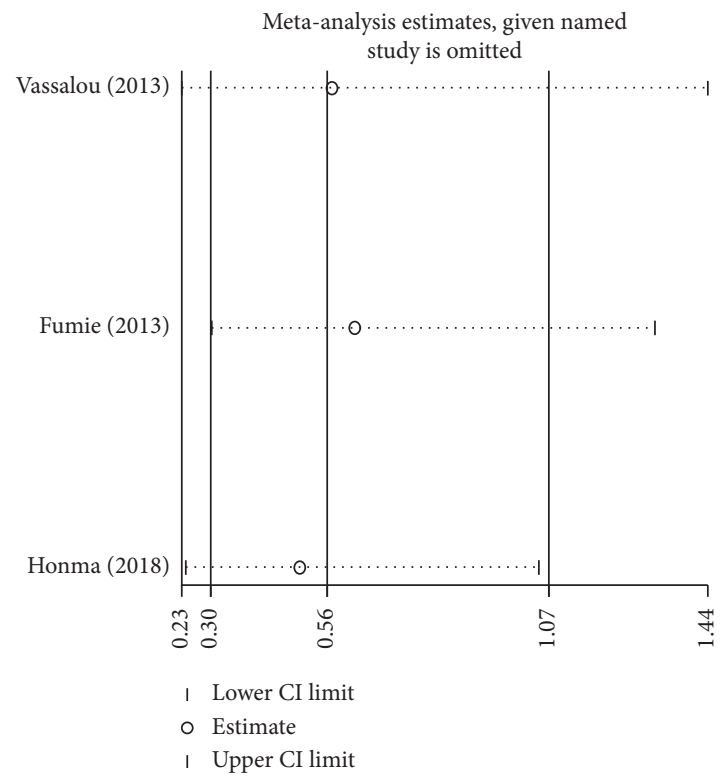

(c)

Figure 4: Sensitivity analysis results. (a). Overall. (b). Asian. (c). Caucasian.

Of course, this study also has some limitations: (1) The methods used in the included literature are basically IHC. When it is used to detect the expression of ERCC1, there are differences in the scoring criteria among the studies. (2) The scope of the selected research is narrow, mostly in Asian countries, only 9 in Europe and America, but none in Africa and other countries. (3) Although IHC is used to detect the expression of ERCC1 in all of the studies, the manufacturer, dilution concentration, and judgment criteria of antibody are not completely consistent, which may affect the results of meta-analysis. (4) The test of publication bias on the overall study and the population in Asian countries shows that there is still a partial publication bias. However, these results should be interpreted with caution, as the criteria for judging gene expression are inconsistent in the selected studies. Sensitivity tests may also be necessary. In addition, prospective studies with larger sample sizes still need to further confirm these findings.

In conclusion, there is a correlation between the high expression of ERCC1 and the chemosensitivity of NSCLC platinum drugs. The low expression of ERCC1 is more sensitive to platinum chemotherapy in patients with advanced NSCLC, especially in Asian population, but not in Caucasians. The state of ERCC1 may be a potential biomarker for predicting the efficacy of platinum chemotherapy in NSCLC. However, considering the limitations of this study, large-scale and well-designed studies are still needed to investigate the factors that may affect the response to platinum chemotherapy. 


\section{Data Availability}

The datasets used and/or analyzed during the present study are available from the corresponding author on reasonable request.

\section{Conflicts of Interest}

The authors declare that there are no conflicts of interest.

\section{References}

[1] R. L. Siegel, K. D. Miller, and A. Jemal, "Cancer statistics, 2018," CA: A Cancer Journal for Clinicians, vol. 68, no. 1, pp. 7-30, 2018.

[2] N. Kensuke, K. Koichi, T. Tomohiro et al., "Survival difference in NSCLC and SCLC patients with diabetes mellitus according to the first-line therapy," Medical Oncology, vol. 30, no. 1, 367 pages, 2013.

[3] M. G. Oser, M. J. Niederst, L. V. Sequist, and J. A. Engelman, "Transformation from non-small-cell lung cancer to smallcell lung cancer: molecular drivers and cells of origin," The Lancet Oncology, vol. 16, no. 4, pp. e165-e172, 2015.

[4] X. Wang, S. Su, S. Li et al., "Development of quality indicators for non-small cell lung cancer care: a first step toward assessing and improving quality of cancer care in China," BMC Cancer, vol. 17, no. 1, 603 pages, 2017.

[5] Y. Lu, J. Cheng, Z. Lin et al., "Pharmacoeconomic analysis for pemetrexed as a maintenance therapy for NSCLC patients with patient assistance program in China," Journal of Medical Economics, vol. 21, no. 1, pp. 60-65, 2018.

[6] R. A. Britten, D. Liu, A. Tessier, M. J. Hutchison, and D. Murray, "ERCC1 expression as a molecular marker of cisplatin resistance in human cervical tumor cells," International Journal of Cancer, vol. 89, no. 5, pp. 453-457, 2000.

[7] J.-S. Ryu, Y.-C. Hong, H.-S. Han et al., "Association between polymorphisms of ERCC1 and XPD and survival in nonsmall-cell lung cancer patients treated with cisplatin combination chemotherapy," Lung Cancer, vol. 44, no. 3, pp. 311-316, 2004.

[8] C. Monika, K. Monika, C. Agnieszka et al., "ECCR1 and NFKB2 polymorphisms as potential biomarkers of non-small cell lung cancer in a polish population," Anticancer Research, vol. 39, no. 6, pp. 3269-3272, 2019.

[9] R. H. Sarah, M. S. Ashley, and S. Maria, "Small-molecule inhibitors targeting DNA repair and DNA repair deficiency in research and cancer therapy," Cell Chemical Biology, vol. 24, no. 9, pp. 1101-1119, 2017.

[10] E. Reed, "Platinum-DNA adduct, nucleotide excision repair and platinum based anti-cancer chemotherapy," Cancer Treatment Reviews, vol. 24, no. 5, pp. 331-344, 1998.

[11] R. Nisato, J.-C. Tille, and M. Pepper, "Lymphangiogenesis and tumor metastasis," Thrombosis and Haemostasis, vol. 90, no. 10, pp. 591-597, 2003.

[12] D. Su, S. Ma, P. Liu et al., "Genetic polymorphisms and treatment response in advanced non-small cell lung cancer," Lung Cancer, vol. 56, no. 2, pp. 281-288, 2007.

[13] G. R. Simon, S. Sharma, A. Cantor, P. Smith, and G. Bepler, "ERCC1 expression is a predictor of survival in resected patients with non-small cell lung cancer," Chest, vol. 127, no. 3, pp. 978-983, 2005.

[14] S. Andreas, "Critical evaluation of the Newcastle-Ottawa scale for the assessment of the quality of nonrandomized studies in meta-analyses," European Journal of Epidemiology, vol. 25, no. 9, pp. 603-605, 2010.

[15] H. Vassalou, E. Stathopoulos, G. Fiolitaki et al., "Excisionrepair-cross-complement-1 protein as a prognostic factor in patients with advanced non-small cell lung cancer treated with platinum-based first-line chemotherapy," Lung Cancer, vol. 82, no. 2, pp. 324-329, 2013.

[16] Y. Fumie, A. Koichi, Y. Tsukasa et al., "Prognostic value of EGFR mutation and ERCC1 in patients with non-small cell lung cancer undergoing platinum-based chemotherapy," PLoS One, vol. 8, no. 8, Article ID e71356, 2013.

[17] W. Xin, Z. Jun, Y. Lu et al., "Positive expression of ERCC1 predicts a poorer platinum-based treatment outcome in Chinese patients with advanced non-small-cell lung cancer," Medical Oncology, vol. 27, no. 2, pp. 484-490, 2010.

[18] Z. Q. Gao, B. H. Han, C. Shen et al., "Clinical research of individualized therapy in advanced non-small cell lung cancer guiding by detection of ERCC1 protein," China Oncology, vol. 23, pp. 328-333, 2013.

[19] H. F. Wang, J. Q. Yang, X. H. Wang et al., "Relationship between expression of ERCC1 and drug therapeutic effect of cisplatin chemotherapy in advanced non- small cell lung cancer," Journal of the Fourth Military Medical University, vol. 23, pp. 351-354, 2009.

[20] L. Shan, Z. G. Han, L. Liu et al., "ERCC1 and BRCA1 expressions in advanced non-small cell lung cancer and their relationship with cisplatin resistance," Tumor, vol. 29, pp. 571-574, 2009.

[21] W. W. Wang, G. F. Lee, Z. W. Wu et al., "Significance of detection of ERCC1 expression in platinum-based neoadjuvant chemotherapy for stage III non-small cell lung cancer," Shandong Medical Journal, vol. 495 pages, 2009.

[22] L. L. Lee and X. Q. Liu, "Correlation of expression of ERCC1/ RRM1 with cisplatin combined with gemcitabine chemotherapy sensitivity and prognosis in non-small cell lung cancer," Bulletin of the Academy of Military Medical Sciences, vol. 34, pp. 265-268, 2010.

[23] N. Yang, J. Q. Han, and W. Sheng, "Relationship of expressions of RRM1 and ERCC1 proteins with response and prognosis in advanced NSCLC patients receiving cisplatin combined with gemcitabine chemotherapy," Journal of Shandong University (Health Science), vol. 49, pp. 89-93, 2011.

[24] J.-Y. Han, G. K. Lee, K. Y. Lim, Y. J. Lee, B. H. Nam, and J. S. Lee, "ERCC1 expression-based randomized phase II study of gemcitabine/cisplatin versus irinotecan/cisplatin in patients with advanced non-small cell lung cancer," Cancer Research and Treatment, vol. 49, no. 3, pp. 678-687, 2017.

[25] K. Azuma, T. Sasada, A. Kawahara et al., "Expression of ERCC1 and class III $\beta$-tubulin in non-small cell lung cancer patients treated with a combination of cisplatin/docetaxel and concurrent thoracic irradiation," Cancer Chemotherapy and Pharmacology, vol. 64, no. 3, pp. 565-573, 2009.

[26] H. W. Lee, Y.-W. Choi, J. H. Han et al., "Expression of excision repair cross-complementation group 1 protein predicts poor outcome in advanced non-small cell lung cancer patients treated with platinum-based doublet chemotherapy," Lung Cancer, vol. 65, no. 3, pp. 377-382, 2009.

[27] S. Ota, G. Ishii, K. Goto et al., "Immunohistochemical expression of BCRP and ERCC1 in biopsy specimen predicts survival in advanced non-small-cell lung cancer treated with cisplatin-based chemotherapy," Lung Cancer, vol. 64, no. 1, pp. 98-104, 2009.

[28] H. N. Honma, M. W. Perroud Jr., A. M. Morcillo, J. Vassallo, and L. Zambon, "Response to cytotoxic chemotherapy and 
overall survival in non-small cell lung cancer patients with positive or negative ERCC1 expression," Jornal Brasileiro de Pneumologia, vol. 44, no. 3, pp. 245-246, 2018.

[29] E. Reed, "Alkylating agents and platinum," Current Opinion in Oncology, vol. 3, no. 6, pp. 1055-1059, 1991.

[30] C. Ping, L. Jian, C. Yong-Chang et al., "The functional status of DNA repair pathways determines the sensitization effect to cisplatin in non-small cell lung cancer cells," Cellular Oncology, vol. 39, no. 6, pp. 511-522, 2016.

[31] E. Jeffery, "Monitoring gene expression profile changes in ovarian carcinomas using cDNA microarray," Gene, vol. 229, no. 1-2, pp. 101-108, 1999.

[32] P. J. Mchugh, V. J. Spanswick, and J. A. Hartley, "Repair of DNA interstrand crosslinks: molecular mechanisms and clinical relevance," The Lancet Oncology, vol. 2, no. 8, pp. 483-490, 2001.

[33] C. Fang, Y. X. Chen, N. Y. Wu et al., "MiR-488 inhibits proliferation and cisplatin sensibility in non-small-cell lung cancer (NSCLC) cells by activating the eIF3a-mediated NER signaling pathway," Scientific Reports, vol. 7, no. 1, p. 40384, 2017.

[34] R. Rosell, M. Taron, A. Barnadas, G. Scagliotti, C. Sarries, and B. Roig, "Nucleotide excision repair pathways involved in cisplatin resistance in non-small-cell lung cancer," Cancer Control, vol. 10, no. 4, pp. 297-305, 2003.

[35] C. Michele, H. Karen, J. M. Claire et al., "XPA versus ERCC1 as chemosensitising agents to cisplatin and mitomycin $\mathrm{C}$ in prostate cancer cells: role of ERCC1 in homologous recombination repair," Biochemical Pharmacology, vol. 72, no. 2, pp. 166-175, 2006.

[36] K. A. Olaussen, A. Dunant, P. Fouret et al., "DNA repair by ERCC1 in non-small-cell lung cancer and cisplatin-based adjuvant chemotherapy," The New England Journal of Medicine, vol. 355, no. 10, pp. 983-991, 2006.

[37] E. C. Seyhan, S. Altin, E. Cetinkaya et al., "Prognostic significance of ERCC1 expression in resected non small cell lung carcinoma," Annals of Thoracic and Cardiovascular Surgery, vol. 17, no. 2, pp. 110-117, 2011.

[38] L. M. Sad, S. G. Younis, and M. M. Elity, "Prognostic and predictive role of ERCC1 protein expression in locally advanced stage III non-small cell lung cancer," Medical oncology, vol. 31, no. 7, p. 58, 2014.

[39] H. M. Wang, W. Zahng, B. H. Han et al., "Association of expression of ERCC 1 with survival and resistance to cisplatinin patients with I-III A NSCLC," Journal of Shanghai Jiaotong University, vol. 28, pp. 1072-1077, 2008.

[40] Y. Dong, W. Ping, A. Guangyu et al., "Prognostic potential of ERCC1 protein expression and clinicopathologic factors in stage III/N2 non-small cell lung cancer," Journal of Cardiothoracic Surgery, vol. 8, no. 1, p. 149, 2013. 